\title{
Social Analysis in Project Lending: Writing New Rules and Changing Old Practices
}

\author{
Susanna Price
}

\section{Introduction}

In 1984 the World Bank placed social analysis formally into the rulebook. For the first time amongst multilateral development banks (MDBs), the Bank's rulebook integrated social analysis into a key operational checkpoint before project approval. This took the form of "sociological aspects" as a policy methodology of the World Bank's investment project appraisal, on a par with economic, financial, institutional, technical, and environmental analyses.

The policies on resettlement and indigenous peoples represented a breakthrough in defining requirements to protect the people adversely affected by Bank projects, but the appraisal rule had a wider scope and intent. However crucial, resettlement and indigenous people's policies were, by definition, applicable only to a proportion of the Bank's investment projects triggering those policies. The new rule was of a different character-applying to the Bank's entire portfolio of investment projects, it provided a proactive strategy to enhance project success and sustainability through social design. It formally launched social, poverty, and gender analysis in operational form, together with participative approaches to project planning and design, recognizing the people as ultimate users for whom loans were intended. Social analysis had formally come of age-but never realized its potential.

Described as an "enabling framework" (Davis 2004) and "conceptually pathbreaking" (Dani 2003: 8) the rule-Operational Manual Statement (OMS) 2.20was "not systematically implemented" (ibid). The notion of a rule for social analysis in the rulebook, however, gained traction both inside and beyond the Bank, proving that rules can be both ignored in implementation, but also have wider impact by virtue of their existence. This chapter examines this paradox, tracing the story of the

\footnotetext{
S. Price $(\bowtie)$

College of Asia and the Pacific, Australian National University, Canberra, ACT, Australia e-mail: susanna.price@anu.edu.au
} 
social analysis component of the appraisal rule, its reason for being, how it came about, and its impact on World Bank operations, and beyond.

\section{Challenging Social Pioneers}

Development was bypassing the poor. After decades of lending at the World Bank President MacNamara emphasised:

... the critical relationship of social equity to economic growth. . .the need to design development strategies that would bring greater benefits to the poorest groups in the developing countries-particularly to the approximately 40 per cent of their populations who are neither contributing significantly to economic growth nor sharing equitably in economic progress (MacNamara 1973).

The dominant paradigm was shifting, as rural producers emerged from the mists of their supposedly immutable belief systems to become potential future consumers contributing to economic growth. As pragmatic economic actors they became part of a modernizing economic growth story. Projects that intended to benefit them should, logically, be re-designed to capture that potential also.

MacNamara proposed to lend significantly more money-and to assess the distribution of benefits arising from that expenditure. He proposed several new lending foci to increase the productivity of small agriculturalists: land tenure reform, access to credit, better input supplies, reorganised services, and institutions. The World Bank formed a Rural Development Division to manage these foci and, in 1974, hired its first staff sociologist to work primarily on rural social formations and co-operatives. Other changes included increased financing, new initiatives in evaluation, and in environmental assessment, and more money for social sectors.

Realizing McNamara's vision to reach the lowest $40 \%$ of people triggered broader operational questions-how to identify specific groups, engage their support, and to understand the social context that shaped their lives. This chapter explores why it was necessary to write new content into the Bank's policies and procedures, and so into the investment projects.

The absence of social perspectives was not surprising. Multilateral Development Bank (MDB) charters did not mention people or the social context in which lending operations would unfold. For decades, consequently, large sums were spent without knowing how people lived, worked, and networked, what they believed, valued, prioritised, and could access, and whether they had benefitted as intended. National plans abstractedly highlighting improved human well-being rarely specified targets or programs. Borrowers and lenders alike conceptualized "social" or "human factors" at best as residual, of little account, or at worst, as "social constraints" to economic growth transformations. Local institutions were considered impediments, not building blocks, to development. When such investments failed those intractable “social constraints" offered a scapegoat (Apthorpe 1970; Price 2015). 
The benefits of economic growth were widely assumed to outweigh any adverse social consequences. Development agencies favoured building urban industrial sectors emulating developed country "progress" from which benefits might trickle downwards. Superimposing external growth-generating inputs, planners ignored pre-existing local socio-economic forms of production and trading (Hart 1970). Iron-clad tradition was thought to stifle individual initiative, despite emerging work showing multiple negotiated reciprocities in complex, and dynamic, agrarian societies (Scott 1976). Intended beneficiaries of urban and rural health, nutrition, and education services, were rarely consulted in planning those services (Rosser 1970; Apthorpe 1970), let alone taking responsibility for setting and implementing their own programs.

Women's role and productivity were routinely ignored. Esther Boserup's work (1970) questioned the widespread assumption that lending was gender neutral, demonstrating that projects could harm women because planners were gender blind to women's roles.

Neither the MDBs nor their borrowers checked before approval for environmental and social costs on differentiated groups of people in the project's zone of impact, nor matched projects to sociological features to improve the prospects for their success. They required no public consultation on investment decisions before approval, nor participation of the intended beneficiaries in project design.

\section{Emerging Social Perspectives}

Before 1974, the World Bank had never appointed anthropologists, rural sociologists, and other social researchers to in-house positions. Their skills were not deemed relevant to the core business of planning and managing lending. Gloria Davis, the first anthropologist appointed to the World Bank in 1978, attributed the Bank's social concepts and practices to a "broad spectrum of individuals and institutions both inside and outside the Bank" (Davis 2004: iv). In 1973 Vice president Warren Baum circulated a paper entitled A Report with Recommendations on the Use of Anthropology in Project Operations of the World Bank Group (Cochrane and Naronha 1973). The paper recommended increased social input into Bank projects by hiring social specialists. Bank staff supported this idea but did not know how to do it.

The idea that anthropological and sociological knowledge could enhance project impacts was not new. Goodenough's 1963 classic, Cooperation and Change: An Anthropological approach to Community Development, in asserting that any development project not founded on a thorough understanding of the client culture was doomed to failure, had earlier provided development workers with a crash course in cultural anthropology. Community development approaches themselves had diverse and longstanding origins which would influence some lenders more than others. Yet anthropologists, emphasizing the importance of understanding the unique characteristics of each society, may have inadvertently reinforced the notion of immutable 
tradition accompanied by intractable local institutions, in which social scientists served only as translators to the more enlightened shock troops of economic development. Moreover, in studying cultures as unique constructs, anthropologists may have overlooked the broader economic and political transformations occurring in rural societies.

The question of how to translate social concerns into specific planning steps was being addressed during the 1960s, for example, at the Institute of Development Studies in the UK (Apthorpe 1970). Social specialists had been involved in ex-post evaluation for some years, providing valuable feedback on project outcomes-but had no clear feedback link into project selection and design to avoid replicating mistakes.

Optimistically assuming that social and cultural factors were irrelevant, planners blindly believed in the transformative value of "progressive" thought, to justify project approval. They assumed successful models were easily replicable anywhere. Albert O. Hirschman, an economist, conversely, opposed such assumptions as deepening the risk of failure. His notion of a "Hiding Hand" might unexpectedly, through human ingenuity, rescue the project from failure. ${ }^{1}$ More importantly for subsequent developments, Hirschman found each project, upon close inspection, to "represent a unique combination of experiences and consequences, of direct and indirect effects", resulting from the varied interplay between the "structural characteristics" of projects, and the "social and political environment" in which they were situated (Hirschman 1967: 178). This approach recognized the importance of social and political factors in economic analysis of projects-factors with which he assumed that project planners could work to develop strategies for behavioral change for better projects. Hirschman brought these novel ideas into the World Bank.

The US National Environmental Protection Act (NEPA 1969/70) raised social issues. The first law linking the prediction of environmental impacts to investment planning in a regulatory framework, NEPA required an Environmental Impact Statement (EIS) if proposed investments involved US federal land, laws, or funds. Based upon feasibility study, decision makers could select the design option with least environmental cost, mitigating any remaining impacts. EIS required examination of social and cultural, as well as physical, impacts. NEPA widened investment decision-making to encompass human and cultural factors through what became Social Impact Assessment (SIA). This called for efforts to define social impacts; to predict changes in the distribution of those impacts; to identify the winners and losers of investment decision-making; and, in case of investment approval, to formulate mitigative measures to protect the personal and property rights of the losers (Barrow 2000).

These ideas had barely taken hold in 1973, however, at NEPA, let alone among the World Bank's borrower governments around the globe. The Bank's development investments unfolded in developing country frameworks that had little regulatory

\footnotetext{
${ }^{1}$ Hirschman's Hiding Hand has stimulated a recent debate on whether it is a Benevolent Hiding Hand or a Malevolent Hiding Hand (Flyvbjerg and Sunstein 2016: 1).
} 
recognition of social risks or impacts, with very few social specialists. EIA and SIA parameters were still evolving subject to US court cases (Burdge et al. 2004). A mere subset of EIA, SIA languished in the environmental paradigm. Moreover, as first conceptualized, SIA emphasized the predictive impact of given project alternatives, rather than proactive social design or, even better, project selection.

The United States Congress legislated seminal changes in 1973 and 1975, promoting policy and budgetary efforts to increase employment and more equitable income opportunities for the poor. In an unprecedented step, the law makers required that the poor majority participate in the "decisions that shape their lives" (Hoben 1982). This participatory goal also called for greater attention "to interrelationships among technology, institutions, and economic, social, environmental and cultural factors" (ibid). As a result, USAID required, from September 1975, a Social Soundness Analysis, that aimed to reach beyond statistical data to address the core cultural values and beliefs invoked in many projects seeking to change production, resource use, food supply and social organization-particularly in poor communities (Cochrane 2019). It mandated the participation of those affected in planning projects.

Social soundness analysis had mixed results. Irritating non-social specialists with additional time and expense requirements, it came too late in the project cycle to make an impact for many social specialists (Hoben 1982). It increased exponentially the in-house and contracted anthropologists hired by USAID during the 1970s (ibid). Nonetheless, after only 5 years USAID found that this novel requirement had improved the design of about one quarter of USAID projects processed. Other multilateral agencies such as FAO and WHO were hiring social specialists; as did bilateral agencies, Sweden, Canada and Australia (AusAID 1989).

\section{Social Analysis: Internal Bank Track}

The World Bank President had, in 1973, declared that the poorest $40 \%$ were missing out on increases in GDP in developing countries, being instead consigned to malnutrition, illiteracy, and squalor-but this farsighted analysis was not accompanied by mandatory requirements on a par with USAID's Social Soundness Analysis. In 1974 the World Bank had reached the paradoxical situation of having a just and farsighted new macro-policy, while its analytical procedures languished, unreformed. In accordance with its official charter, the World Bank's "core business" required only economic, financial, technical, and commercial analysis for preparing new growth projects. The procedural document (1971) governing project preparation envisaged no hint of sociological input, let alone the notion that the people mattered in this process.

Staff faced a challenge: they must identify and reach the poorest $40 \%$, design projects capable of reaching and engaging them, and succeed in reducing poverty tangibly. The Bank's first professional sociologist, Michael Cernea, appointed in 1974, diagnosed retrospectively: 
The absence of social analysis from the Bank's arsenal of project crafting tools, was, however, at that time, part of a wider problem. What was missing was not just the "technology" of doing social analysis. The gap was much wider: it was philosophical and cognitive. A theory or social philosophy about the role of people as development actors was missing. In the social sciences, work on "inducing development" was then still an emerging domain. Development sociology and development anthropology themselves were young new fields of research and thinking, rather than disciplines or sub-disciplines with rich research records, codified bodies of knowledge, or mature epistemology.... The Bank would not yet have an articulated overall methodology for inducing social change, except by supplying finance and purchasing technology. Much was still to be invented, tested, articulated on the social dimensions of development investment projects (Cernea 2013).

The obsolete 1971 guideline on project appraisal continued to be used during the entire decade of the 1970s. The guideline provided no way of assessing whether the benefits of the project being appraised would benefit the lowest $40 \%$ of the population, nor whether those hard-to-reach people had been consulted. ${ }^{2}$

Cernea in 1977 created a "Bank Sociological Group" (BSG) for the tiny but growing band of in-house staff social specialists, and other staff interested in social and cultural issues. The group's wide ranging, open, intellectual, and practical discussions attracted many, including several Bank staff who had hitherto hidden advanced sociological training. Often, the topics would be one or more Bank projects which had either failed spectacularly or succeeded remarkably. In either case, the presenters were invited to analyze-detached, and with the benefit of hindsight — what led to that success or failure. From there, the discussion of social and cultural circumstances of any development project took flight in the open and 'informal space' of the BSG. Speakers from the Bank's Board of Executive Directors, and most senior management, accepted the BSG invitations to speak to the group; as did talented external social scientists knowledgeable about the Bank's projects. ${ }^{3}$

Since division chiefs responsible for hiring staff had no idea what sociologists or anthropologists could contribute, Cernea organized Bank seminars addressing Vice President Warren Baum's paper defining the typical tasks staff carried out at key points of the project cycle. Promoted as Model of Entry Points for Sociological Knowledge in the Project Cycle, an amended document alerted staff, especially middle level managers, to what professional social specialists could contribute at each key step, from the earliest project identification; through to post-project evaluation. Being a purposive intervention for accelerating and targeting development, projects offered scope to involve the intended project beneficiaries. Cernea's additions to Baum's model showed how social science knowledge about the

\footnotetext{
${ }^{2}$ Cernea recounted that in 1974 , newly arrived and assigned his first project appraisal mission, he asked what his tasks would be. He was given the 1971 Operations Manual Statement (OMS) on project appraisal, to read and find out. He panicked. Nothing in the OMS required the skills and contributions that he, as a sociologist, could make. That memory stayed with him over the years, reinforced by the conviction that the 1971 document was obsolete and inadequate (Cernea pers. com. January 2019).
}

${ }^{3}$ See Nuket Kardam's PhD on the BSG's influence on the IBRD (Kardam 1993). 
project area, strategy, and objectives could enhance, and enrich, the staff understanding at each project cycle stage, thereby enhancing demand for social specialists on Teams. ${ }^{4}$

It was important to show that social specialists could do more than simply "translate" local culture into non-specialist terms, based on their research among ethnic populations: they could substantially contribute to the planning and design of projects. Cernea's informal guide entitled Minimal and Optimal Requirements for Social Information in Appraisal Reports defined the sociological knowledge that was necessary as a basis for project approval (Cernea 1987; 1995).

The emerging discipline of the sociology of development offered the theoretical argument for an alternative model for projects, a model in which the "social actors are the pivotal element, the central core around which all other resources should be marshaled for action" (Cernea 2013; 2015). In 1982 these initiatives paved the way for the formulation of a template for the "sociological aspects" of appraisal of projects. A Bank Task Force which wrote a new "Operational Manual Statement ("OMS") 5 " 2.20 on "Project Appraisal" included "Sociological Aspects" of Appraisal. Management approved it in 1984.

\section{Appraising "Sociological Aspects"}

In naming "sociological aspects" as an integral element of project appraisal, along with economic, financial, technical, institutional, and environmental analysis (World Bank 1984), OMS 2.20 brought substantive sociological knowledge into the standard for judging whether a project was suitable for Bank financing. Mapping new cognitive and epistemological terrain, OMS 2.20 set projects a standard to meet before their approval. The "Sociological Aspects"-or, as it came to be termed, "social analysis" of OMS 2.20 allowed clearer definition of the project 'target groups' or the 'intended beneficiaries', together with methods designed to ensure that different sub-groups participated in, and benefited from, project interventions.

OMS 2.20 required project staff responsible for processing the project loanswhether they were economic, technical, or financial analysts-to identify the population toward whom a project was directed and to give them an active role in the project itself: "projects designed to assist specific beneficiaries ... depend [for their success] upon participation by the beneficiaries." Each project required "the explicit consideration of the social organization patterns, traditions, and values bearing upon the feasibility, implementation, and operation of projects; and the pursuit of objectives such as poverty alleviation" (World Bank 1984, OMS 2.20, para. 55).

\footnotetext{
${ }^{4}$ The paper was subsequently published in Schwartzweller (ed.). (Cernea 1987).

${ }^{5}$ Operational Manual Statements, subsequently Operational Directives then Operational Policies, were the binding policies approved by management.
} 
In four significant requirements, the scope of sociological analysis at appraisal necessarily included:

a) The socio-cultural and demographic characteristics of local beneficiaries;

b) The social organization of productive activities of the population in the project area;

c) The cultural acceptability of the project, its compatibility with the behavior and needs of the aimed as beneficiaries; and

d) The social strategy for project implementation and post completion operation, able to elicit and sustain beneficiaries' participation (para. 56)

Taking each point in turn, OMS 2.20 first demanded verification that the project design was based upon a sound understanding of the social and gender organization of productive activities-also a basis for analyzing the distribution of project benefits among different social groups (para 57) and thus understanding social equity. Project activities must be demonstrably "culturally acceptable" to the intended beneficiaries, that is: understandable, agreed to, and capable of being operated and maintained by them (para 61).

Second, the document formally introduced the principle of people's participation advocated by Cernea, and colleagues such as Gloria Davis and Maritta Koch-Weser. The OMS called for a "social strategy for eliciting the full commitment to the project of the beneficiaries and their institutions"-a principle that should operate right through the project cycle and should be supported by capacity building for effective participation.

Third, the OMS required (again for the first time in a Bank normative document) a gender perspective, or analysis of women's possible benefits or risks of negative impacts from a given project. Bank staff and borrowers were asked to think in advance about "the contribution that women could make to achieving the project's goals" and were also warned against "changes which the project will introduce that might be disadvantageous to women" (para 62).

Fourth, the OMS cautioned against imposing social risks on the project's population. If such risks had a high likelihood, a pilot or postponement for adequate counter-risk planning was recommended.

Social soundness data must be researched, collected, and employed by the borrowing country and studied by Bank's staff long before the final appraisal mission, necessitating Divisional staff to request the borrowing agency to engage social specialists to conduct social research, and to assemble the data for use from the start in project preparation. This raised awareness of the importance of social information in borrowing countries and triggered the inclusion of local sociologists and anthropologists in the country preparation teams. Impetus from 1975 onwards from USAID and other bilateral and multilateral agencies, together with modest but growing impact from environmental regulatory frameworks which included SIA all cumulatively helped develop country expertise. ${ }^{6}$

\footnotetext{
${ }^{6}$ For instance, a leading Indian anthropologist, Professor HM Mathur, wrote an article entitled: "From Onlookers to Participants: How the Role of Social Scientists in India's Development has Changed."
} 
President McNamara had emphasized the critical relationship of social equity to economic growth and poverty reduction (1973). OMS 2.20 required distributional data to inform an economic analysis - but recognized methodological difficulties. Lack of country consensus might obstruct analysis of the appropriate trade-offs between efficiency, equity, and regional balances. Where reduction of income disparities and poverty were important project objectives, the economic appraisal must include an assessment of the project's contribution to these objectives.

Mostly, qualitative assessment sufficed to demonstrate the worth of projects with marginal economic returns but possibly high-income distribution of benefits. Quantitative assessment required allocation of costs and benefits according to the income status of the affected population-which the OMS 2.20 recognized as difficult, for example in determining poverty "target" income levels of beneficiaries; in allocating costs and benefits; and in achieving consensus on the weights which should be given to costs and benefits at different income levels (OMS 2.20).

The OMS allowed discretion in addressing social equity. Social analysis could inform economic analysis by providing social data, and a means of mobilizing stakeholder engagement for consensus building, but cooperation seems limited on assessing social equity and whether social benefits outweighed social costs.

\section{Disseminating Social Analysis}

Once approved, the Bank's social specialist community promoted OMS 2.20 internally and externally among borrowers, incorporating the ideas into influential book publications. The Bank's first sociological book (1985), Putting People First: Sociological Variables in Development Projects (Cernea 1985) was based on the central tenet that "people are-and should be-the starting point, the center, and the end goal of each development effort." It advocated a changed approach to planning internationally financed development projects for sectors including irrigation, forestry, cooperatives, livestock, roads, and other rural infrastructure, demonstrating how the principles could be applied in project experience.

Growing internal understanding of social perspectives did not necessarily translate into adoption of the rule, however. Placing social analysis, even into such a crucial point in the rulebook as project appraisal, by no means secured universal attention to it, since "compliance with the new guidelines was far from general and the institutional mechanisms for absorbing them were insufficient. Simply placing new rules on the Bank's internal guidebooks appeared to be not enough for triggering the profound changes in staff work patterns that meeting the new demands implied. .." (Cernea and Kudat 1997: 6). As a new dimension in project work, social analysis needed consistent application, knowledgeable bank and borrower practitioners, plus time and resources for field research, and for integrating findings into the project design.

Newly independent former Soviet Union countries began joining the Bank as borrowers without any lending history. Analysis of these social transitions filled 
critical data gaps essential for loan processing. Gloria Davis wrote how, in 1997, Ayse Kudat led the social assessment thematic team to clarify and deepen the concept of social analysis as "social assessment", making it

\begin{abstract}
more systematic and rigorous. The objectives of social assessment were formally linked to poverty reduction and to other positive social outcomes such as enhancing social inclusion, strengthening social cohesion, increasing social capital, and reducing adverse social impacts. With increasing rigor, this generation of social assessments had a substantial impact on project design.... where quantitative evidence of social impacts and their economic consequences was especially crucial to changing the approaches of policy makers... Through these efforts, and complementary work in the regions, the idea of social assessment was widely disseminated both inside and outside the Bank, and social assessments were increasingly mainstreamed in country programs and in the national procedures of some countries (Davis 2004: 22).
\end{abstract}

Social assessment in this context facilitated, rather than inhibited, loan processing, easing its acceptance. Even this deepened form of social assessment, however, did not necessarily generate a specific "product" additional to the designa Resettlement Action Plan, for example. Absence of a visible product made it easier to mainstream the social analysis in OMS 2.20 into other Bank "rules" over time. A 2001 Board-endorsed Gender Strategy and a revised Operational Policy (OP), and Bank Procedure (BP) 4.20, for example, helped client countries address gender disparities that obstruct development. In 2001 OP 4.20 replaced OMS 2.20 for gender, thereby scaling down coverage only to projects in sectors and themes identified by the country strategy. An independent evaluation in 2009 recommended greater attention to accountability, monitoring, and results; and called for gender integration at the project level as had applied with OMS 2.20 (IEG 2009).

A new rule (OD 4.15 on Poverty Reduction, approved in 1991) addressed poverty issues. The Environmental and Social Framework (ESF) that became effective in 2017 now applies to the Bank's investment project financing, passing primary responsibility to borrowers for the necessary social assessments. The ESF identifies a range of potential social risks, including resettlement and indigeneity, particularly those which fall disproportionately on the disadvantaged and vulnerable. Environment and Social Statement (ESS) 10 deals with stakeholder engagement for investment projects and proposes actions to facilitate participation.

A recent view of the World Bank Inspection Reports (World Bank 2017) identified consultation, participation, and disclosure as key issues that had arisen in close to $90 \%$ of the 120 inspection requests since 1993. OMS 2.20 was phased out in 2012, leaving no formal "rule" to integrate social analysis into appraisal for investment projects. The next section examines the experience of another MDB in setting social analysis into the rulebook, before drawing lessons for the Conclusion. 


\section{Asia Pacific Regional: An Alternative Track}

Founded in 1966, the MDB Asian Development Bank (ADB)'s model resembled other development lenders of the time. ADB worked almost exclusively with borrower government agencies, initially on infrastructure loans. In 1973, ADB's President called for development to be brought "directly to the people" (McCawley 2017). Surveys in the mid-1970s revealed that Asia's marginal farmers and landless laborers, particularly those in remote, dryland, and upland areas outside the wellirrigated schemes with their new high yielding varieties, were beset by social problems arising from joblessness, malnutrition, and hunger. Per capita grain production had barely risen given population growth rates, while nutritional levels declined. This situation prompted ADB's Board in 1978 to agree to increase lending for agriculture and rural development by 20\% per year until 1982 (ibid).

This marginal group clearly needed attention. As in the World Bank case, however, effective ways had to be found within lending modalities to reach them. ADB staff began working on new approaches to bring project benefits to two groups missing out: women; and poorer, often indigenous small-scale producers. Reaching both groups required new thinking, challenging routine models.

After introducing a policy on women in development (WID) to Australia's bilateral aid agency (1975), ADB staff member Christine Whitlam introduced the concept of ADB Country Briefing Papers on women's role in development. Gender differences in access to and benefits from development reflected in country data from these papers showed women facing major barriers: heavy workloads, restricted access to education and health services, restricted access to planning and loss of status from some projects. Country strategy and programming exercises were envisaged to counter such barriers, and empower women to participate in project design, so as to enhance their opportunities and benefits. Such efforts greatly increased institution-wide awareness and attention to gender issues in ADB's lending operations. A Bank-wide WID policy was proposed to build upon this work and refine gender approaches by sector (Christine Whitlam pers. com. 25 May 2019). The WID Policy, prepared by Yuriko Uehara, and approved by the ADB's Board in 1985, aimed to integrate women into all ADB operations, throughout the project cycle; and to target special strategies for their participation and benefits, through continued WID country assessments. A committee chaired by Christine Whitlam was subsequently established to overcome barriers to women's recruitment and retention on ADB professional staff. Shireen Lateef later advanced the WID policy under a Gender and Development policy (1998) and program. The 1985 original WID policy was the first of its kind among the MDBs.

Cedric Saldanha, a staff member with a background in social justice in India, began piloting new agricultural and fisheries project models for marginal and poor producers, including indigenous peoples-people who regularly missed out on benefits from standard projects working through government outreach. The best way to reach such people was through mobilisation and empowerment methods that directly addressed their needs and priorities, adapting new knowledge, 
understanding, and practice to local circumstances. Community-based organisations had the skills and experience to work with farmer and irrigator organisations-but engaging them would require changes in loan preparation and lending procedures to allow time and space for these new processes to unfold. The resultant loans challenged some international lending advice. The World Bank, for example, advised against intervening in the financial markets with directed finance. Nonetheless, committed to bringing microfinance to the poor, Saldanha successfully prepared for approval a Microcredit Project, breaking new ground in multilateral lending, by learning from the Grameen Bank model used in Bangladesh. In that project, ADB persuaded the Department of Trade and Industry (DTI) of the Philippines government to on-lend money borrowed from ADB to local microcredit groups for on-lending to small and micro entrepreneurs (Cedric Saldanha, pers. com February 2019).

Country surveys of NGOs followed. The Board's approval of a policy on The Bank's Cooperation with Nongovernment Organizations, in 1987 gave higher visibility and priority to the issues, and authority to staff advocating such approaches which they had not had before. Staff also recognized the need for practical guidance on "How to do it" that could take lessons learned more widely across the organization and its borrowers. In another important initiative Bill Staub developed guidelines for project benefit monitoring and evaluation methods that would allow the assessment of project outcomes on intended beneficiaries, and others impacted.

These pioneers also faced barriers. Christine Whitlam recalled the challenges of being one of only 13 professional women on ADB staff in 1981 (Christine Whitlam pers. com 25 May 2019). Cedric Saldanha recalled having to cope with "very substantial resistance from within the organization. ADB was dominated by economists and engineers. Social science and governance experts were given very little recognition or hearing in the early days. This did change substantially by the early 1990s" (Cedric Saldanha pers. com 2017) — when ADB began appointing social development, resettlement, and poverty specialists.

By the end of the 1980s global attention focussed again on poverty. Recognising that, despite some strong country growth, more than half the world's poor lived in Asia, in 1988 ADB established an internal Task Force on Poverty Alleviation to identify ways of prioritizing attention to poverty within its projects. The following year ADB invited five Asian experts, including Amartya Sen, to recommend on ADB's role. Their report recommended, among other suggestions, a balanced approach that included social and environmental goals, and a greater focus on poverty reduction through projects directly benefitting the poor. The concept of poverty reduction itself was broadening to include empowerment of people to benefit from education, health, and gender equity.

ADB's Taskforce on Project Quality in 1994 recommended a major change in focus: more attention to project implementation on the ground and less to achieving higher lending volumes. Board members were also requesting that ADB introduce safeguard policies on environment, involuntary resettlement and indigenous peoples. The donors froze their financial replenishments pending resolution of these issues. The change from the "loan approval culture" to a focus on local needs, 
capacity building, and changed internal accountability was, however, too radical for the organization (McCawley 2017: 191). The President promised to address these issues through setting strategic objectives and on this basis the donors resumed financing. ADB sought a way to address the new poverty reduction, gender, and social issues, together with safeguards, without compromising its lending volume.

In 1993 Sam Rao, Director of a newly formed Social Development Unit, produced official Guidelines on Incorporation of Social Dimensions into ADB Operations $(1993)^{7}$ that addressed global concerns for poverty reduction following a decade of structural adjustment. ADB's Medium Term Strategic Framework (1992-1995) reaffirmed the economic growth objective, and added poverty reduction, improved status of women, human resource development and environmental management (ibid). Growth quality, sustainability, and equity demanded a stronger focus on 'issues of social significance based on a participatory approach to development, greater gender and social analysis, benefit monitoring and evaluation, and cooperation with...NGOs' (ADB 1992: 47). Social analysis would help realize poverty reduction in lending operations. This approach incorporated the earlierdeveloped, innovative community-based loan models designed to benefit the poor directly, complementing gender initiatives to reach women.

The Guidelines linked the social dimensions to the country operational strategies that formed the basis of the country operational programs. In this way social analysis, integrated into the entire country macro programming and sector analyses, set the basis for subsequent project selection-and then into all stages of the project cycle.

In 1994 the Handbook for Incorporation of Social Dimensions in Projects recommended an initial social scoping for all projects to start early in identifying and addressing the social dimensions during project preparation-mandated in the 1995 Board-approved Policy on Involuntary Resettlement. The social scoping, which included gender analysis, aimed to ensure that no project went to the Board without integrating social dimensions into its design.

Management approved these rules in the 1997 Operations Manual (OM) Section-the "rulebook" (now updated as OM Section C3 on Bank Policy and Operational Procedures on Incorporation of Social Dimensions in ADB Operations). The social "rule", still operational, and subject to compliance review (ADB 2018), encompasses public and private sector investment projects funded by a loans, grants, and other means (equity and guarantees); and program loans. First principles are defined:

... social elements such as gender, ethnicity, race, caste, age, and others, influence people's decision making, access to services, resources, opportunities, and ability to cope with risks. These variables affect the character of the institutions (formal and informal rules, norms, and values) that determine the level and nature of people's access and capability... operations can help significantly reduce poverty, inequality, and vulnerability by transforming

\footnotetext{
${ }^{7}$ Drawing upon a publication entitled Guidelines for the Social Analysis of Development Projects incorporating community-based methods developed in ADB's pioneering projects (Bysouth and O’Sullivan 1991).
} 
institutions so they promote inclusiveness, equity, empowerment, and social security (ADB 2010: 1).

In early 1997 Management also approved Bank Policies and Operational Procedures on Gender and Development, on Involuntary Resettlement, and on Governance, followed, in 2000, by Indigenous Peoples and Anti-corruption. ADB's then President Chino declared an over-arching Poverty Reduction objective in 1999, in which inclusive social development is one of three pillars. He also raised the proportion of women in senior and professional positions in the Bank.

\section{Comparative Analysis}

In both banks, the social "rule", complementing an economic development mandate set in founding charters, situated projects amongst specific groups of stakeholders, and planned for their participation and benefits. In both cases, new work patterns, which were intended to enhance the match between projects and their chosen beneficiaries, challenged standard project lending models, time frames and practices.

OMS 2.20 intended to act at a critical point before loan approval, to ensure the entire project design was socially sound. The World Bank's new, more systematically applied rule for investment projects, the ESF, is primarily a social and environmental safeguard management tool. As a safeguard primarily, the ESF reflects new thinking in identifying and mitigating a range of social risks and impacts; and briefly touches on human rights, including through a ban on forced evictions. Being focused on safeguards, however, it does not require overall project social design to match beneficiary circumstances; nor analysis on a par with economic and financial analysis before loan approval; nor address questions on project benefits distribution and social equity. It does not set a key point before loan approval to question whether the project's long-term benefits will justify its wider environmental and social costs, taking account of the distribution among different social groups. MacNamara's 1973 call to address the critical relationship of social equity to economic growth remains unaddressed.

The lending imperative has only intensified since then, shaping responses. OMS 2.20 was most successful as an enabling framework for social analysis in expanded form to help create the knowledge base needed for effective lending, primarily in the former Soviet Union countries. Subsequent successful loans following Community Driven Development (CDD) principles assign to communities the responsibility for programming and spending significant resources, particularly facilitating expenditure where government programs are weak, and unable to meet spending conditions and targets (Guggenheim and Wong 2018). Both cases facilitated, rather than impeded, lending flows. ADB has faced similar lending pressures throughout also, as evidenced, for example, in 1994 when the Taskforce on Project Quality recommendations were deemed too constraining for a bank. ADB searched for a way to 
address the new social and poverty agenda without compromising its lending volume.

Writing social rules has necessitated a fine balance between social soundness and the "core business" of lending continuity. Weathering decades of evolving "soft" agendas for poverty reduction, gender, and social development, the lending imperative itself has survived and thrived. Publications, policy documents, and "rules" contend that both social and gender analysis not only make good economic sense, but also foster local support which is necessary for project sustainability. Yet the lending imperative, that "core business" for any bank, has too often prioritized loan approvals above their outcomes, and lending quantity above quality. In Saldanha's words:

...whatever the banks' rules and policies, in implementation the crucial factor is-what is the leadership commitment, policies, attitudes, approaches within the borrowing government agencies? The banks have little patience for the hard work required in influencing or changing local attitudes and governance within borrowing governments. They have, I think, failed the greatest challenge of development. They have always been primarily focused on how much they can lend, and to which sectors (Cedric Saldanha, pers. com February 2019).

The underlying Bank charters have not changed. Not all new development lenders, meanwhile, prioritize poverty reduction. Achieving the Sustainable Development Goals, (SDGs) might work best with community-based models as developed in ADB; or along the lines of the World Bank's CDD, in which a menu of options for communities to consider might certainly include infrastructure. Instead, however, the MDBs together present a foregone conclusion, a vision of a vast, and necessary, infrastructure spend which also mobilizes significant private sector financing (World Bank 2018), in which risk analysis focuses more often on risks to project investments rather than risks to people affected by them (ibid).

The views of intended beneficiaries may differ from those of the "borrowers"the national, sectoral, and provincial level agency staff. Prioritizing choices, strategies, and approaches suggested by sub-groups of people, may be time-consumingand might lack importance to national officers. Finding the right balance between the skills, timeframes, and perspectives necessary to engage the poor and understand their priorities, compared with those of writing briefs and preparing loans for speedy approval by the head office, presents a continuing challenge (Cochrane 2019). Marginal groups not favored by governments may be particularly at risk of being sidelined, overridden or subjected to human rights violations. Processes that may continue to be viewed in purely technical terms - such as services provision, agricultural intensification or land titling — risk harm without careful social analysis.

Each MDB has its own unique culture. The two MDBs discussed here followed different strategies in formulating social rules. Underlying structural similarities and lending constraints have, nonetheless, built co-operative frameworks upon those early contacts. ADB's Sam Rao visited Michael Cernea in Washington on several occasions, obtaining a copy of OMS 2.20, with its strategic importance as the first MDB formal rule on social-and gender-analysis. 


\section{Conclusion}

Reducing poverty demanded operational change. This chapter demonstrated how the process of approving new rules triggered discourse in both banks bridging all disciplines, to fill knowledge gaps, move perceptions, and create momentum for organizational change. In both cases the "social" domain was defined broadly, interlinking complementary themes of poverty reduction and gender equity.

Second, lending limits can shift. By addressing objectives of gender equity and poverty reduction, and by operationalizing them in different contexts, the rules helped change the policy mandate for lending-ADB on WID and, later, poverty reduction; World Bank on poverty reduction. These policies changed the underlying conceptualization of "good development" which, in turn, permitted some shifts in lending practices. This meant, thirdly, that rules embodied some flexibility in authorizing resource mobilization to achieve those policy objectives.

Fourth, the codification of new concepts and practices at one moment can, together with a management open to new ideas, become a baseline for change, allowing specialists to take stock, review progress and learn lessons. Rules offer a base for subsequent monitoring and evaluation of outcomes that may deliver important lessons for future projects. For example, ADB's WID country papers formed a baseline for measuring subsequent country change in women's wellbeing.

Fifth, the rules on social analysis could be, and were, later used as a basis for inspection, as both MDBs adopted more sophisticated and adversarial accountability mechanisms.

We began with the paradox of a far-reaching rule that was not systematically implemented. Despite the later risk of non-compliance, rules could be ignored or flouted. Rules are only effective insofar as management continues to support them and to provide enough time and resources to implement them-and the limit here has consistently been the lending imperative, and its underlying conceptualization of what constitutes good development. MDB rules required fine tuning to allow incremental change whilst not impeding "core business" by slowing lending significantly. The scope for change was greatest where those rules expanded the conceptualization of "core business"; and also, where the rules fostered new lending patterns and project models that enabled, rather than impeded, lending flows.

Borrowers set the limits or go elsewhere for financing in a lending environment marked by rapidly diversifying financing sources. The trend in shifting MDB project responsibilities to borrowers raises the question of country standards for SIA where aims, procedures, capacities, and outcomes are uneven. SIA has broadened globally to include a wide range of issues, including human rights, packaged in management plans. In some countries, however, SIA, if mandated and practiced at all, may be defined as a tool to address a narrower range of risks of importance only to project sponsors, financiers or government rather than to people.

There is unfinished business, both for lenders and borrowers. MacNamara in 1973 called for attention to the critical relationship of social equity to economic growth. This call has never been addressed fully. Rules offered, at best, only 
tentative guidance and significant discretion in addressing the central questions of whether fully calculated benefits outweigh social costs, and how they are distributed among social groups. Beyond that, broader structural shifts and impacts remain unexplored and unaddressed in the context of lending. Sustainability assumes increasing urgency. The challenges of poverty reduction, equality, sustainability, and growth are vast, and perhaps irreconcilable (World Inequality Report 2018). These questions continue as tensions escalate around global and country-specific inequality.

Social pioneers laid the groundwork for questioning pre-existing norms. They made new subjects visible, engaged them in planning projects, and codified these approaches in social "rules". They envisaged continued cooperation among social development specialists, reaching beyond institutional and country borders; and encompassing local partners. Changing global circumstances now heighten new fears about limits to growth, sustainability, and human survival. In such testing times social analysts must brave new frontiers: social and gender equity in interaction with sustainability. The social analysis "rules" have come a long way, but they have some way to go to be realized fully (Fig. 1).

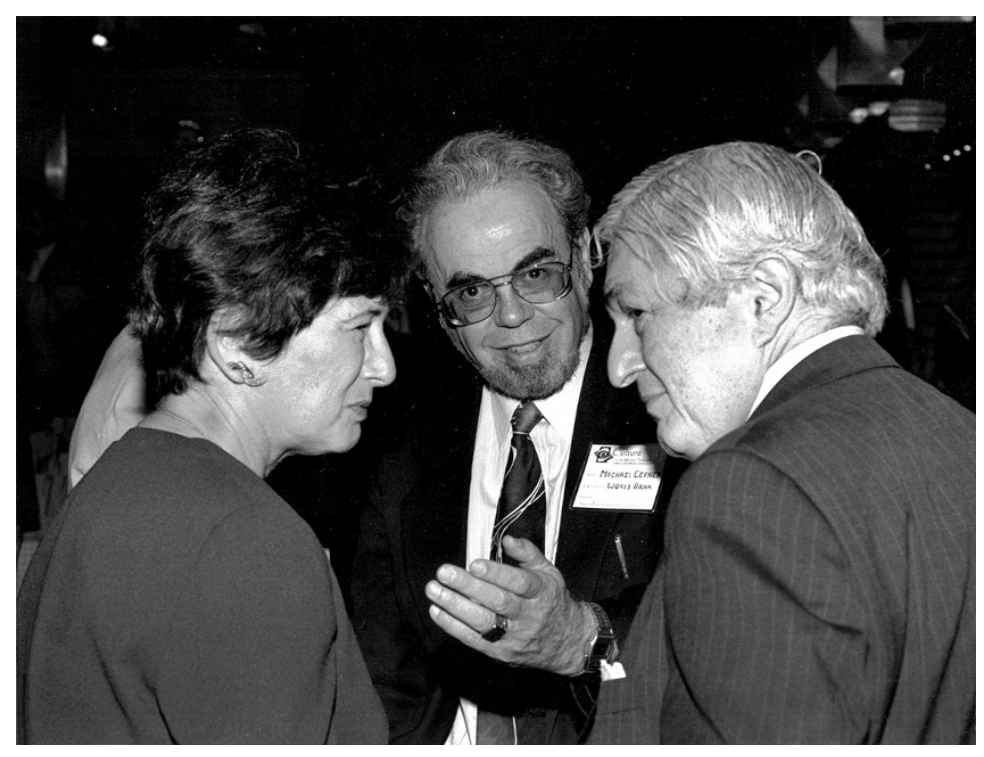

Fig. 1 President James D. Wolfensohn at Michael Cernea's retirement party, together with Michael's wife, the anthropologist Ruth Fredman Cernea 
Acknowledgement The author thanks the editors, Dr. Scott Guggenheim and Dr. Maritta KochWeser; and Professor Michael Cernea, all formerly World Bank staff; Ms. Christine Whitlam and Mr. Cedric Saldanha, former staff of ADB; Dr. Warren A. Van Wicklin III for valuable suggestions; and Ms. Arielle Klein for editing an earlier draft.

\section{References}

Apthorpe, R. (Ed.). (1970). People, planning and development studies: Some reflections on social planning. London: Frank Cas.

Asian Development Bank. (1992). Medium term strategic framework (1992-1995). Manila: ADB.

Asian Development Bank. (1993). ADB guidelines on incorporation of social dimensions into $A D B$ operations. Manila.

Asian Development Bank. (1995). Policy on involuntary resettlement. Manila.

Asian Development Bank. (1999). Poverty reduction strategy. Manila.

Asian Development Bank. (2010). Operations manual. OM C3/BP 'Incorporation of social dimensions into ADB operations'. Accessed 25 May 2019. https://www.adb.org/sites/default/files/ institutional-document/31483/om-c3.pdf

Asian Development Bank. (2018). ADB accountability mechanism annual report 2017. Manila: ADB.

AusAID. (1989). Social analysis and community participation guidelines. Canberra: Australian Agency for International Development.

Barrow, C. J. (2000). Social impact assessment: An introduction. London: Arnold.

Boserup, E. (1970). Women's role in economic development. London: Earthscan.

Burdge, R. J. et al. (2004). The concepts, process and methods of social impact assessment. Middleton, WI: The Social Ecology Press.

Bysouth, K., \& O'Sullivan, N. (1991) Guidelines for the social analysis of development projects. Manila: ADB

Cernea, M. M. (Ed.). (1985) Putting people first: Sociological variables in rural development (1st edn). Oxford University Press, World Bank.

Cernea, M. M. (1987). Entrance points for sociological knowledge in planned rural development. In H. Schwartzweller (Ed.). Research in rural sociology. Jay Press. http://documents.worldbank. org/curated/en/518211468147838917/pdf/659280WP0Box360entrance0points01987.pdf

Cernea, M. M. (1995) Social organization and development anthropology: The 1995 Malinowski Award Lecture. ESSD. Washington, DC: World Bank.

Cernea, M. (2013). Draft. Landmarks in development: The introduction of social analysis. In S. Price \& K. Robinson (Eds.), Making a difference (Vol. 2013). Berghahn, NY: Oxford.

Cernea, M. M. (2015). Landmarks in development: The introduction of social analysis. In S. Price \& K. Robinson (Eds.), Making a difference. Berghahn, NY. 2013 First draft.

Cernea, M. M., \& Kudat, A. (Eds.). (1997). Social assessments for better development: Case studies in Russia and Central Asia. Washington, DC: World Bank.

Cochrane, G. (2019). Management by seclusion: A critique of World Bank promises to end global poverty. Berghahn Books.

Cochrane, G., \& Naronha, R. (1973). Report with recommendations on the use of anthropology in project operations of the World Bank Group. Washington DC: Report for the World Bank.

Dani, A. (2003, November 24-25). From mitigating impacts to improving outcomes. Paper to a conference on new directions in impact assessment for development: Methods and practice, Manchester.

Davis, G. (2004) A history of the social development network in the World Bank, 1973-2002. Washington, DC: The World Bank (Social Development Paper No. 56). 
Flyvbjerg, B., \& Sunstein, C. R. (2016). The principle of the malevolent hiding hand; or, the planning fallacy writ large. In Social change social research: An international quarterly (Vol. 83, pp. 979-1004). Johns Hopkins University Press. Winter 2016.

Guggenheim, S., \& Wong, S. (2018). Community driven development: Myths and realities. Policy Research Working Paper 8435. World Bank Group Social, Urban and Resilience Global Practice.

Hart, K. (1970). Small scale entrepreneurs in Ghana and development planning. In R. Apthorpe (Ed.), People, planning and development studies: Reflections on social planning. London: Frank Cass.

Hirschman, A. O. (1967). Development projects observed. Washington DC: Brookings.

Hoben, A. (1982). Anthropologists and development. Annual Review of Anthropology, 11, 349-375.

Independent Evaluation Group (IEG). World Bank, 2009 Fast Track Brief. Gender and development: An evaluation of World Bank support, 2002-08. Accessed 12 May 2019.

Kardam, N. (1993). Development approaches and the role of policy advocacy: The case of the World Bank. World Development, 21(11), 1773-1786.

MacNamara. (1973). Nairobi speech. Washington DC: World Bank. Accessed August 2019. https://www.worldbank.org/en/about/archives/president-menamara-nairobi-speech-1973.

McCawley, P. (2017). Banking on the future of Asia and the Pacific: 50 years of the Asian Development Bank. Manila: ADB.

Price, S. (2015). Introduction: Making economic growth socially sustainable? In S. Price \& K. Robinson (Eds.), Making a difference? Social assessment policy and praxis and its emergence in China (pp. 1-30). New York: Berghahn Books.

Rosser, C. (1970). Action planning in Calcutta: The problem of community participation. In R. Apthorpe (Ed.), People, planning and development studies: Some reflections on social planning. London: Frank Cass.

Scott, J. C. (1976). The moral economy of the peasant: Rebellion and subsistence in Southeast Asia. New Haven, CT: Yale University Press.

World Bank. (1971). Project appraisal. OMS. Washington, DC.

World Bank. (1984). Project appraisal. OMS 2.20. Washington, DC.

World Bank. (2017). The inspection panel emerging series no. 4, Consultation, participation and disclosure of information. Accessed 2 May 2019. https://inspectionpanel.org/sites/ inspectionpanel.org/files/publications/ConsultationParticipationandDisclosureInformation.pdf

World Bank. (2018). World Bank Group and the 2030 agenda. Washington DC: World Bank.

World Inequality Laboratory. (2018). World inequality report. Accessed 20 May 2019. https:// wir2018.wid.world/executive-summary.html

Susanna Price is currently a Lecturer (Hon) in the College of Asia and the Pacific at the Australian National University (ANU) and Council Member, ANU's Burgmann College. She worked in Ausaid; and in Asian Development Bank (ADB), Manila as Senior Social Development Specialist and lead Resettlement staffer. Her PhD is from Kyoto University, Japan. Prizes include the Praxis Prize, Washington Association of Professional Anthropologists (2003); a CIDA Prize (2000); ADB Presidents Prizes and a Australian Public Service Scholarship for overseas study. Recent publications include Responses to Displacement across Asia-Pacific: Strategies for Development, Disasters and Climate Change and Country Frameworks for Development Displacement and Resettlement, both co-edited volumes for Routledge with Professor Jane Singer. Her latest articles are: "Looking back on development and disaster-related displacement and resettlement, anticipating climate related displacement in the Asia Pacific region" in Asia Pacific Viewpoint 2019; and, with Warren van Wicklin III, Dolores Koenig, John Owen, Chris de Wet and Asmita Kabra: "Risk and Value in Benefit Sharing with Displaced People in Social Change 50 (3): 447-465 2020. She is currently working on options, if any, for survival on a post-apocalyptic planet. 
Open Access This chapter is licensed under the terms of the Creative Commons Attribution 4.0 International License (http://creativecommons.org/licenses/by/4.0/), which permits use, sharing, adaptation, distribution and reproduction in any medium or format, as long as you give appropriate credit to the original author(s) and the source, provide a link to the Creative Commons license and indicate if changes were made.

The images or other third party material in this chapter are included in the chapter's Creative Commons license, unless indicated otherwise in a credit line to the material. If material is not included in the chapter's Creative Commons license and your intended use is not permitted by statutory regulation or exceeds the permitted use, you will need to obtain permission directly from the copyright holder. 